\title{
LOS INDÍGENAS DE BUENOS AIRES A COMIENZOS DEL SIGLO XVIII: LOS REALES PUEBLOS DE INDIOS Y LA DECLINACIÓN DE LA ENCOMIENDA
}

\author{
POR \\ CARLOS MARÍA BIROCCO \\ Universidad de Morón \\ Instituto y Archivo Histórico Municipal de Morón, Argentina
}

Durante el siglo XVII, las encomiendas de buenos aires fueron desapareciendo debido a la incidencia de las enfermedades infecciosas, la fuga y la mestización. A comienzos del siglo siguiente los pocos indigenas encomendados fueron agrupados en pueblos bajo administración real y se los organizó bajo el sistema de mita. En ellos se los sometió al reparto de textiles y a una dieta de proteínas de origen vacuno, a fin de que no distrajeran esfuerzos en la agricultura y se concentraran en el servicio de mita.

Palabras clave: Buenos Aires, reales pueblos de indios, sistema de mita, alimentación.

\section{EL FRACASO EN LA SEDENTARIZACIÓN DE LAS ETNIAS PAMPEANAS ORIGINARIAS}

Cuando en 1580 la ciudad de Buenos Aires fue fundada por segunda vez, sus pobladores entraron en contacto con varias etnias indígenas y hallaron que ninguna de ellas se hallaba en condiciones de suministrar excedentes agrícolas suficientes para sustentarlos. Uno de esos grupos, los guaraníes asentados en las costas de los ríos Paraná y de la Plata, practicaban una rudimentaria agricultura del maíz y la calabaza desmalezando la tierra por medio de la quema. Éstos habían dejado su impronta cultural sobre las etnias pampeanas que habitaban el nordeste de la actual provincia de Buenos Aires y la vecina provincia de Santa Fe, como los chanás y mbeguás, quienes adquirieron de ellos la práctica de la agricultura de roza, el uso de canoas y la construcción de chozas. Más hacia el sur otro grupo pampeano, los querandíes, aún no se había neoliti- 
zado. Recorrían la llanura desde el Paraná hasta la costa del Atlántico, siguiendo los movimientos estacionales de los cérvidos y las manadas de guanacos, y en sus paradas se guarnecían en rústicos paravientos hechos de pieles de animales, que los españoles llamaron tolderías ${ }^{1}$. Éstos serían los más reacios a sedentarizarse, y en 1620, el gobernador español Diego de Góngora afirmaría que los pocos querandíes que habían podido ser reducidos a encomienda eran «de costumbres bestiales, sin policía ni gobierno».

En 1582 Juan de Garay, el fundador de la ciudad, hizo el primer reparto de caciques e indios entre los vecinos principales. Aunque muchas de las parcialidades que les señaló jamás llegaron a ser sometidas, con ello dio principio al régimen de encomienda en Buenos Aires. Dada la naturaleza no excedentaria de los indígenas pampeanos, se les exigió la prestación de servicios personales antes que el pago de tributo en especie. Pero cuando en 1611 el oidor Francisco de Alfaro visitó la ciudad, prohibió expresamente las prestaciones en trabajo y dio indicaciones precisas para que los indígenas encomendados fueran agrupados en reducciones, ordenando una estricta separación residencial entre naturales y colonos ${ }^{2}$. Como la región estaba escasamente poblada, la segregación territorial no presentó mayores inconvenientes. Atendiendo a las instrucciones dadas por el oidor, el gobernador Diego Marín Negrón asentó en 1611 a la parcialidad del cacique Juan Bagual a orillas del río Areco, a unos $100 \mathrm{~km}$ de la ciudad, asignándole la enorme rinconada que se formaba en la confluencia entre dicho río y la Cañada Honda. Esta reducción, bautizada como Nuestra Señora de la Estrella pero conocida más tarde como San Joseph del Bagual, fue visitada por el gobernador Hernandarias de Saavedra en 1615, quien halló en ella 50 indígenas con sus familias y encargó su adoctrinamiento a los franciscanos. En los meses que siguieron se fundaron otras dos, cuya catequización fue también encargada a los religiosos de esa orden. Una de ellas, la de San Juan Bautista, fue mejor conocida como Tubichaminí (pequeño jefe, en guaraní) por haberse asentado en ella la parcialidad del cacique de ese nombre, constituida por unos 150 individuos, presuntamente mbeguás. La otra reducción, que recibió el nombre de Santiago del Baradero, se constituyó en 1616 con 250 chanás.

En 1620 el gobernador Diego de Góngora realizó la primera evaluación censal de la población indígena de Buenos Aires. Encontró en la ciudad 103 indios de servicio, mientras que otros 668 estaban distribuidos en las reducciones de Bagual, Tubichaminí y Baradero. En los años que siguieron una combi-

1 Para un mayor conocimiento de las etnias pampeanas, consúltese: Conlazo, 1982: 7-19. González Lebrero, 2004: 24-44.

2 Mörner, 1999: 120-122. 
nación de alzamientos y epidemias provocó el despoblamiento de esos asentamientos, hasta que a mediados de esa década el gobernador Francisco de Céspedes consiguió restablecerlos, si bien en forma efímera. Céspedes logró sujetar a la parcialidad de los baguales, que se había levantado, y la restableció en Areco. Asimismo, enfrentó desórdenes en Tubichaminí, donde el cacique Telomyán Condic, que no quiso someterse a los españoles, fue desterrado al Brasil y reemplazado en el cacicato por su hijo. Fundó, además, una nueva reducción de indios querandíes, que llamó Caguané, con un territorio que se extendía a ambas márgenes del río Arrecifes, a unos $150 \mathrm{~km}$ de la ciudad. En 1628 nombró nuevos corregidores para las cuatro reducciones que existían, a quienes encargó que mantuvieran reunidos a los indios para que «no anden vagando», obligándolos a hacer sementeras y a aprender la doctrina cristiana ${ }^{3}$.

Con excepción de los chanás de Santiago de Baradero, las parcialidades reducidas mostraron particular resistencia a la sedentarización. San Juan Bautista de Tubichaminí fue la primera de dichas reducciones en desaparecer. Todavía se la menciona en 1636, pero en 1659 había sido abandonada por sus habitantes, que se habían rebelado contra sus encomenderos y unido a una tribu de indios serranos no sometidos, junto a los cuales saquearon las haciendas cercanas $^{4}$. Los indígenas de San Joseph del Bagual y de Caguané experimentaron la misma tendencia a abandonar sus poblados. En 1642 se pidió a fray Bartolomé de Lencinas, clérigo doctrinante de Santiago del Baradero, que también se hiciera cargo de esas reducciones, pero éste se declaró incapaz de hacerlo «por ser los dichos baguales y caguanés gente andariega que lo más del año no asisten en sus tierras» ${ }^{5}$. Es posible que estos grupos siguieran retirándose tierra adentro en búsqueda de venados y otras presas, desplazamientos de carácter estacional que llevaban a cabo desde antes de la conquista y que estaban en condiciones de retomar cuando el control de los españoles se hacía más laxo ${ }^{6}$. Ello fue confirmado en 1673 por el párroco de la catedral de Buenos Aires, Gregorio Suárez Cordero, quien refirió que estos indios, aunque encomendados, «gozan de toda libertad vagando como bestias por las campañas... no tienen labranzas por vagabundos y así se sustentan con carnes de animales que cazan, que comen cruda y seca al sol» ${ }^{7}$.

3 Peña, 1916, Vol. V: 168.

4 Torre Revello, 1963: 235.

5 Actis, 1943, Vol. I: 21-26.

${ }^{6}$ Lebrero: 32-39.

7 Carta del Dr. Gregorio Suárez Cordero a la reina, 1 de septiembre de 1673, en Torre Revello, 1941: 286-289. 
De la reducción del Bagual apenas tenemos noticias más allá de mediados del siglo XVII. Se sabe que fue mudada de una a otra banda del río Areco y que se le construyó una iglesia, pero hacia 1690 ésta se encontraba ya en ruinas. En diciembre de 1677 no quedaban más que doce indios sujetos al joven cacique Pedro Bagual. Éste pretendió, a fines de esa centuria, reivindicar las tierras que habían pertenecido a su parcialidad y estaban entonces en propiedad del general Miguel de Riblos, pero perdió el pleito que inició contra este influyente vecino porteño ${ }^{8}$. En cuanto a los indios de Caguané, estos hicieron abandono de la reducción durante el gobierno de Andrés de Robles, hacia 1675. Proyectaron su fuga en dos oportunidades, la primera de ellas sin éxito, pues fueron capturados y reagrupados con un grupo de indios serranos recientemente sometidos en un paraje próximo al Riachuelo, la laguna de Aguirre. A la segunda tentativa consiguieron mudar sus tolderías a la Punta del Sauce, en Córdoba, donde permanecieron durante dos décadas. Las pocas familias que los españoles lograron retener fueron conducidas a Santiago del Baradero, pero terminaron por huir y reunirse con el resto de la parcialidad en las sierras cordobesas, movidos por los malos tratos que recibían del corregidor de esa reducción, el capitán Juan Ruiz9.

En la segunda mitad del siglo XVII hubo nuevos intentos de reducir a los indígenas pampeanos en poblados segregados. Uno de éstos se levantó fuera del territorio bonaerense: hacia 1662 se estableció en Entre Ríos la reducción de Santo Domingo Soriano, cuyos habitantes eran chanás de la reducción de Baradero que habían escapado al territorio mesopotámico al desatarse una epidemia. Otro fue la reducción de la parcialidad de los vilachichis, que en 1665 fueron radicados más allá de las últimas suertes de estancia repartidas sobre el río Luján, a unos $80 \mathrm{~km}$ de Buenos Aires ${ }^{10}$. A éstos se sumó un grupo no pampeano: en 1666 fueron deportados desde el Tucumán varias familias de indios quilmes y acalianes, luego de haber resistido durante décadas en los valles Calchaquíes, y se los asentó a unos $50 \mathrm{~km}$ de Buenos Aires, formando con ellos la reducción de Santa Cruz de los Quilmes ${ }^{11}$.

La tendencia observada en los aborígenes pampeanos de retornar al nomadismo provocó el rápido despoblamiento de aquellas efímeras poblaciones. $\mathrm{La}$ dispersión pudo haberse debido a múltiples causas: su falta de adaptación a las pautas de trabajo impuestas por los españoles, las numerosas bajas producidas

8 Sobre la consolidación del latifundio de este opulento vecino de Buenos Aires, Birocco

LIII: 1 (Sevilla, 1996): 73-75.

9 Torre Revello, 1941, Vol. I: 301-314.

10 Torre Revello, 1963: 235-236.

11 Sors de Tricerri, 1937: 33-35. 
por las enfermedades infecciosas, sus hábitos de cazadores errantes $\mathrm{y}$, sobre todo, la cercana presencia de la frontera, que facilitaba su fuga y les permitía reunirse con otros grupos aún no sometidos, retomando sus antiguos circuitos de migración y cacería. A fines del siglo XVII, los encomenderos reforzaron su control sobre las pocas familias que no huyeron, a las que mantuvieron sirviendo en sus chacras y estancias: la otra cara del despoblamiento fue el proceso de yanaconización a que se vieron sometidos estos indígenas, que se convirtieron en servidores personales de los españoles y terminaron mezclándose con los esclavos negros y peones mestizos que vivían en sus fincas rurales ${ }^{12}$. Sólo sobrevivieron las antiguas reducciones que fueron puestas bajo la administración directa de la Corona: los reales pueblos de indios de Santiago del Baradero y Santa Cruz de los Quilmes.

\section{LAS ENCOMIENDAS PORTEÑAS A COMIENZOS DEL SIGLO XVIII}

Debido a su escasez de mano de obra indígena, Buenos Aires contrastaba con otras ciudades de las gobernaciones del Río de la Plata, Paraguay y Tucumán. Las cifras de que disponemos demuestran que las encomiendas habían ido desapareciendo a partir del último tercio del siglo XVII. En 1673 la ciudad contaba con 22 vecinos encomenderos, entre los que se hallaban repartidos 233 indios; cuatro años más tarde, los encomenderos eran 26 y los indios sometidos a ellos 240. En el cuarto de siglo que siguió, la mayor parte de las encomiendas quedó vacante por deceso de sus titulares. Ello explica que en 1705 los vecinos encomenderos se hubieran reducido a 8 , entre quienes se hallaban repartidos 95 indios tributarios.

En 1711 se hizo un último intento de agrupar a los pocos naturales que se hallaban encomendados en una nueva reducción, la de San Francisco Xavier de Luján. Se trató, en realidad, de una maniobra del gobernador Velasco y Tejada, que buscó apropiarse del trabajo de los indígenas, sustrayéndolos de la órbita de los encomenderos y organizándolos bajo el sistema de la mita. Se estableció que los indígenas entre 18 y 50 años pagaran a la Hacienda un tributo de $5 \frac{1}{2}$ pesos anuales en plata o especie, con opción de servir a cambio durante dos meses. Se limitaron, además, las obligaciones que tenían con sus encomenderos: "si voluntariamente quisieren conchabarse el tiempo que tuvieren libre para asistir a sembrar, segar o para faenas de campaña con sus encomenderos o con otras personas lo podrán ejecutar con licencia de este gobierno o

12 Tomamos el concepto de yanaconización en la acepción aplicada para el caso del Paraguay de Garavaglia, 1983: 269. 
de su corregidor» ${ }^{13}$. La reducción se estableció en la estancia de Gregorio de Matos en Luján, a unos $60 \mathrm{kms}$ de Buenos Aires, recibiendo como doctrinante al fraile dominico Juan de Bustos. Pero se despobló cuando Felipe V mandó intervenir estas provincias por el pesquisidor Mutiloa y Andueza, en 1713, y el gobernador Velasco fue encarcelado, acusado de contrabando con los franceses. El asentamiento fue abandonado y los indios volvieron al servicio personal de sus encomenderos.

A partir de entonces, ya no tenemos noticia de las encomiendas de Buenos Aires. Estos indígenas, según parece, se mezclaron con el resto de la población de casta de la ciudad. La historia de uno de esos grupos, perteneciente a Hernando Rivera Mondragón, sirve para atestiguarlo. En 1655, este vecino se convirtió en tercer cabeza de una encomienda de indios chanás que habían pertenecido a su abuelo, Sebastián de Orduña Mondragón, y luego a su madre, doña Juana de Manzanares ${ }^{14}$. En 1710 sólo quedaban tres de ellos a su servicio. Cuando el gobernador Velasco proyectó la fundación de la reducción de San Francisco Xavier, Rivera Mondragón consiguió que no le fueran quitados alegando que los suyos no eran querandíes ni mbeguás, sino chanás, de idioma y costumbres distintas a las de éstos. Según explicó, eran

de diferente lengua de la que hablan los otros, y que nunca se retiran ni van a ninguna otra parte y que siempre están en mi casa y chacra, porque estos son católicos cristianos desde que nacieron, y en estando en el pueblo oyen misa y se confiesan y comulgan cuando lo manda nuestra Santa Madre Iglesia y se casan por ella y están bien instruidos en la doctrina cristiana.

A continuación de este pedido de excepción que elevó al gobernador, Rivera Mondragón agregó un listado de los indios de su encomienda, con el siguiente detalle:

Fernando, viejo de casi ochenta años viudo, éste tiene tres hijos que sólo son los que me sirven llamados Pascual, Juan y Esteban.

Sebastián su sobrino de éste, viudo y viejo que tampoco éste me sirve, tiene una hija llamada Mariana casada con Juan indio chileno, no tiene hijos.

Matheo, viejo y medio ciego que tampoco me sirve de nada, casado con Elvira, tiene dos hijas casadas. Sebastiana con Agustín mestizo natural del Reino del Perú tiene un hijo muchacho de cinco a seis años y una hijita de dos años. La otra hija

13 Acta de fundación del real pueblo de San Francisco Xavier, 9 de abril de 1711, Archivo General de la Nación Argentina [AGN] Sala IX, Legajo 39-9-7, Exp. 5.

14 La encomienda de Rivera Mondragón, vacante por muerte de su madre, le había sido confirmada por el gobernador Pedro de Baigorri Ruiz en 1655, según el Informe presentado por el gobernador Valdés Inclán al Conde de la Monclava, Virrey del Perú, 19 de enero de 1704, Museo Etnográfico «Juan B. Ambrosetti», Copias de Documentos del Archivo General de Indias, Caja H, Expediente 19. 
está casada con un mulato esclavo del teniente Antonio Villoldo donde está con su marido.

María, cuyos padres son muertos y está casada con Antonio indio del Paraguay, tiene tres hijas y un hijo, la hija casada con un indio del Paraguay, los otros tres son muchachos.

Éstos, señor, son cristianos, oyen misa, se confiesan y comulgan y saben la doctrina y viven como tales, y los que han muerto ha sido con los sacramentos y los he enterrado unos en San Juan y otros en Santo Domingo, y desde que los poseo no los he conocido en pueblo que hubiese de chanás sino que siempre han estado en mi chacra y estancia, y aunque tuve algunos de nación beguais que asistían en el Baradero todos con las pestes que ha habido se han muerto, y sólo hay hoy allá uno llamado Bartolomé que nació en mi casa y se crió en ella y agora siete años se me fue y se casó en el Baradero y hasta hoy no lo he visto y éste es de los chanás ${ }^{15}$.

Rivera Mondragón subrayó en ellos sus hábitos sedentarios, la adopción de prácticas rituales cristianas y la hispanización de sus costumbres. Con todo, lo que sobresale en su petición es lo que no buscaba destacar: el proceso de miscigenación que había sufrido este reducido grupo de chanás encomendados. Las modestas dimensiones de éste habían reducido las chances de contraer vínculos endogámicos, y cinco de las mujeres habían casado con individuos extraños a él, tanto indígenas oriundos de otras provincias como sujetos de casta. La imposibilidad de unirse dentro del grupo acarrearía, a la larga, la extinción de la encomienda, y Rivera Mondragón recurrió a estrategias de retención, como la de forzar a la prole zambomestiza de esas uniones exogámicas a mantenerse en su servicio. En 1704 el protector de los naturales, Bernardino Ramírez de Sagues, intervino en defensa de los zambos Agustina y Martín, a los que aquel tenía «violentados en su casa y servicio», considerándolos parte de su encomienda. En el litigio con el protector, Rivera Mondragón justificaba su postura alegando que

Martín y Agustina zambos, mis encomendados... son nacidos y criados en mi casa e hijos de una zamba, hija de un negro mi esclavo y de una india chaná de mi encomienda, habidos fuera de matrimonio así ellos como su madre, los cuales he estado y estoy poseyendo como a indios de la dicha mi encomienda como se practica en todo este Reino, por razón de que los hijos habidos fuera de matrimonio en indias de encomienda, según las reales ordenanzas, deben seguir la naturaleza de sus madres y tributar a los dueños de ellas, y eso aún en los mestizos criándose en ellas ${ }^{16}$.

Además de las ordenanzas regias, el encomendero basaba su parecer en el capítulo XXX del libro II de la Política Indiana de Solórzano Pereyra. Pero el

15 Petición de Hernando Rivera Mondragón a Manuel de Velasco y Tejada, sin fecha [abril de 1711] AGN Sala IX, Legajo 39-9-7, Exp. 5.

16 Presentación de Hernando Rivera Mondragón a Alonso de Valdés Inclán, 9 de agosto de 1704, AGN, Sala IX, Legajo 42-2-6, Exp. 3. 
protector de naturales sostuvo que el cuadro planteado por Rivera Mondragón era inaplicable, por tratarse de los hijos de una zamba y no de una india, es decir, una segunda generación de mestizos. El gobernador Valdés Inclán coincidió con su dictamen.

El pleito entre Rivera Mondragón y el protector de los naturales trae a colación detalles sobre el origen de Martín y Agustina que en otras circunstancias difícilmente se hubieran dado a conocer. La zamba Dominga, madre de éstos, los tuvo en su soltería, fruto del trato sexual con vecinos españoles de la ciudad. El primero fue hijo del alférez Antonio Vallejos, quien lo había reconocido por tal y le había proporcionado alguna vestimenta; en cuanto a la segunda, era hija de otro vecino español, don Juan de Laris, que la asistió en sus necesidades mientras fue soltero, pero dejó de hacerlo cuando pasó a Santa $\mathrm{Fe}$ a casarse. Las indias encomendadas y sus hijas zambomestizas seguían siendo, pues, objetos sexuales de los españoles como en tiempos de la conquista, colocándose fuera de los controles morales pautados por los europeos ${ }^{17}$. Luego del nacimiento de sus vástagos, la zamba Dominga contrajo matrimonio con un indio del Perú y lo acompañó a las provincias de Arriba, a las que éste pasó conchabado, pero a la larga ambos volvieron a Buenos Aires y se afincaron en la chacra de Rivera Mondragón, donde se mantuvieron por más de doce años sembrando el terreno. De esa manera el encomendero, conciente de que los lazos de servidumbre que sus indios mantenían con él se hallaban próximos a caducar, retenía a una india nacida en su casa y a su esposo por medio de vínculos de patronato y contraprestación, conocidos en esta parte de América con el nombre de agregamiento.

\section{LA IMPLEMENTACIÓN DE LA MITA EN LOS REALES PUEBLOS DE INDIOS}

En la primera década del siglo XVIII, ninguno de los poblados indígenas bonaerenses incorporados a la Corona parece haber superado el centenar de tributarios con sus familias. En 1696, los varones adultos en Santa Cruz de los Quilmes sumaban unos 100, sin que podamos deducir el número a que ascendían sus mujeres e hijos. Treinta de ellos se habían mudado a Buenos Aires, quizás forzados por las autoridades, y el resto, aunque vivía en Santa Cruz, debía concurrir a la ciudad para cumplir el servicio de mita en número de 25 por

17 Como ha podido verse, las indias de Buenos Aires, al igual que las de otras regiones ocupadas por los españoles, no sólo se amancebaron con los españoles, sino también con negros, mestizos y mulatos, quienes tuvieron con ellas un comportamiento semejante al que tenía la élite blanca; Esteva Fabregat, 1988: 208-209. 
mes. Hacia 1701, durante el gobierno de Prado y Maldonado, los mitayos que vivían en el real pueblo no eran más que 70, y al finalizar el gobierno de Valdés Inclán, a comienzos de 1708 , habían descendido a $44^{18}$. El pago de sus tributos, volcado en los libros de Caja de la Real Hacienda de Buenos Aires, confirma con leves variantes esas estimaciones: refiere la existencia de 59 tributarios quilmes y acalianes en 1700, 51 en 1701 y 1702, 52 en 1703, 48 en 1704, 46 en 1705, 51 en 1706, 47 en 1707, 42 en 1708, 45 en 1709 y 42 en $1710^{19}$.

Contrariamente a lo que sucedió en Santa Cruz, la población masculina adulta de Santiago del Baradero tuvo un pico de descenso a comienzos del siglo XVIII pero experimentó una recuperación en la década siguiente. Esto puede constatarse en los mismos libros manuales de la Real Hacienda: 24 indios pagaron tributo en 1690, 16 en 1700, 8 entre 1702 y 1704, 16 entre 1706 y 1708 y 23 en $1709^{20}$. Este incremento pudo haberse debido a la radicación de pardos, mestizos e indios foráneos en el poblado, que se habían unido a las indias de chanás y formado familias en él, y a los que se exigió tributo al igual que a los naturales. De la exogamia de los chanás resultaría, no obstante, su descaracterización como etnia. En 1690 el gobernador Herrera y Sotomayor advertía que la mayor parte de los habitantes de Baradero eran «advenedizos y agregados en aquella reducción, por haberse casado en ella y estar connaturalizados ya con mujeres e hijos que han procreado» ${ }^{21}$. En 1722 el gobernador Bruno Mauricio de Zabala se vio obligado a enviar allí un comisionado, a fin de establecer quiénes eran tributarios. De los 22 varones adultos que vivían en este real pueblo, seis eran foráneos casados con indias chanás: un indio guaraní, dos mestizos, un mulato y dos indios cordobeses, uno de los cuales ejercía entonces el cargo de alcalde. El gobernador, remitiéndose a las Ordenanzas de

18 Capitulo que puso el protector de los naturales en la residencia de Alonso de Valdés Inclán, 10 de noviembre de 1708, AGN Sala IX, Legajo 1-1-3, Exp. 2.

19 Los datos sobre tributación de los indios quilmes y acalianes se encuentran en el Libro de Carta Cuenta de Buenos Aires de 1703-1707, AGN, Sala XIII, Legajo 14-1-2.

${ }^{20}$ Los datos sobre la tributación de los habitantes de Santiago del Baradero han sido extraídos del Libro Manual Borrador de la Real Hacienda de Buenos Aires de 1682-1692, AGN, Sala XIII, Legajo 43-2-1 y el Libro de Carta Cuenta de Buenos Aires de 1703-1707, AGN, Sala XIII, Legajo 14-1-2.

21 Informe de Joseph de Herrera y Sotomayor al gobernador Agustín de Robles, 28 de abril de 1690, Museo Etnográfico «Juan B. Ambrosetti», Copias de Documentos del Archivo General de Indias, Caja H, Expediente 2. Algunos de ellos habían huido de encomiendas en las provincias arribeñas: tal el caso de varios indios de tasa del pueblo de Yaquiliguala, pertenecientes a un vecino feudatario de Santiago del Estero, Juan de Paz y Figueroa, que denunció que «en el pueblo del Baradero y en algunas estancias de esta jurisdicción se hallan diferentes indios de la dicha mi encomienda que ha algunos años que andan ausentes». 
Alfaro, dispuso que los hijos de madre india y padre foráneo pagasen tributo, mientras que los negros, mulatos y mestizos que habitaban la Reducción serían exceptuados de hacerlo, pero les ordenó abandonar de inmediato el poblado.

Tanto los quilmes y acalianes de Santa Cruz de los Quilmes como los chanás de Santiago del Baradero fueron organizados de acuerdo con los principios de la república de indios. Surgieron de esa manera cabildos de naturales, en superposición con la autoridad cacical ${ }^{22}$. Ninguna de estas etnias había conocido, antes de ser reducida, los liderazgos permanentes, pero los españoles se los impusieron y los convirtieron en hereditarios. La exención de cargas y tributos de que gozaban los caciques y los alcaldes del cabildo de naturales suponía su colaboración en el funcionamiento de la mita. Esta institución de origen andino, extraña a los indígenas del Río de la Plata, también les fue impuesta, y consistió en el principal servicio que prestaban los varones adultos de los pueblos reales a las autoridades españolas y la vecindad.

El sistema de mita cumplido por los quilmes y acalianes en Santa Cruz de los Quilmes es mejor conocido, mientras que es poco lo que sabemos de cómo se implementó en Santiago del Baradero. Según un informe de 1696, de los 25 indígenas que bajaban desde Santa Cruz mensualmente a cumplir con la mita a la ciudad, dos tercios eran destinados a trabajar en conventos y obras públicas y el resto era repartido entre los vecinos. El Hospital Real de la ciudad, convertido a comienzos del siglo XVII en una casa de recogimiento de doncellas pobres, era una de las instituciones públicas que se servía de esos mitayos. Las cuentas del Hospital refieren que les eran enviados dos o tres meses al año, mientras que en los meses restantes les era imposible hallar alguno para el servicio, debiendo recurrir al conchavo de peones. Además de un jornal de 11/2 real, cada mitayo recibía una ración diaria de harina de semita y yerba ${ }^{23}$.

La escasa disponibilidad de mano de obra mitaya denunciada por la administración del Hospital Real se debía, más que a una disminución en el número de varones adultos en Santa Cruz, a la presión de los gobernadores, que tendieron cada vez más a monopolizar este recurso en detrimento de los conventos y de la vecindad. Eso sucedió particularmente durante los gobiernos de Agustín de Robles, a fines del siglo XVII, y de Alonso de Valdés Inclán y Manuel de Velasco y Tejada, a comienzos del XVIII. En el juicio de residencia a

22 Sobre la institución capitular en Santa Cruz de los Quilmes: Sors de Tricerri, 1937, 37-39. La existencia de alcaldes en Baradero puede constatarse en el padrón de estos indios de 1717; Padrón de Indios de Santiago de Baradero, 20 de noviembre de 1721, AGN Sala IX Legajo 9-1-18.

23 Birocco, 2000: 30-37. 
Valdés Inclán, los indios quilmes «se quejaron del excesivo trabajo en que fueron molestados todo el tiempo en que gobernó... en las penosísimas faenas de la arrobas de cal, ladrillo, teja y sacar rama y leña para los hornos de los bañados de la costa del río» ${ }^{24}$. Apenas se les dejaba tiempo para cuidar sus sementeras, ya que según denunció el protector de los naturales, Francisco de Tagle Bracho, pocos indios quedaban libres durante uno o dos meses al año. A esto se sumaba que no se les habían pagado los jornales de todo un semestre de servicios. El gobernador no negó haberlos empleado en preparar materiales para la reparación del fuerte, sino que alegó que había sido «estilo» de sus antecesores el utilizarlos en ese ramo, y admitió incluso haberles hecho sembrar cebada para sus propias tropillas de caballos.

Los caciques, que resistieron a ese abuso, le respondieron que las reglas originales de la mita habían sido trastocadas. El cacique quilme Martín Salchica afirmaba haber escuchado a los viejos de su pueblo que en tiempos en que se estableció la reducción, mitaban anualmente dos tercios de los tributarios y un tercio permanecía en ésta, lo que garantizaba el cuidado constante de las sementeras. Pero desde que Valdés Inclán disponía libremente de todos ellos, sólo les daba «el tiempo de quince días para sembrar y otros quince para coger, quedándose la mitad en el trabajo de las faenas, la cual mitad tenía otros quince días para sus siembras o recogidas, viniendo la otra mitad al trabajo de las faenas del rey o de algún particular» ${ }^{25}$. Valdés no sólo los había hecho servir en los trabajos de reparación de las fortificaciones de la ciudad, sino que los había trasladado a la Banda Oriental para realizar una vaquería (cacería de ganado cimarrón). El cacique acalián Martín de Anchoca confirmó con ligeras variaciones la versión de Salchica: la mita pautada originariamente reclutaba a la mitad de los indios por vez, pero como desde tiempos del gobernador Agustín de Robles había «quedado poca gente» en Santa Cruz, se obligó a la totalidad de los adultos pasar a las obras de reparación del fuerte de Buenos Aires ${ }^{26}$. De esta carga sólo estaban excluidos los indios principales: los caciques y los miembros del cabildo de naturales.

$\mathrm{Al}$ ir disminuyendo el número de tributarios del pueblo de Santa Cruz de los Quilmes se recargó sobre los cada vez más escasos mitayos el trabajo que

24 Declaración del protector de naturales Francisco de Tagle Bracho en el juicio de residencia de Alonso de Valdés Inclán, 10 de diciembre de 1708, AGN Sala IX, Legajo 1-1-3, Exp. 2.

25 Declaración del cacique quilma Martín Salchica en el juicio de residencia de Alonso de Valdés Inclán, 10 de diciembre de 1708, AGN Sala IX, Legajo 1-1-3, Exp. 2.

26 Declaración del cacique acalián Martín Anchoca en el juicio de residencia de Alonso de Valdés Inclán, 10 de diciembre de 1708, AGN Sala IX, Legajo 1-1-3, Exp. 2. 
antes se distribuía entre una población más numerosa. Además de alterarse las pautas originarias de la mita, establecidas en tiempos de la deportación, la servidumbre se extendió a las mujeres. En 1702 se levantaron cargos contra el capitán Bernabé Caravallo, corregidor de los quilmes, que se había apoderado de dos muchachas para su servicio bajo el pretexto de adoctrinarlas ${ }^{27}$. También en tiempos del gobernador Valdés Inclán las indias viudas y solteras serían obligadas a servir a particulares, para lo cual fueron trasladadas a la ciudad ${ }^{28}$.

En Santa Cruz de los Quilmes y Santiago del Baradero, la implementación de la mita y el pago del tributo estaban fuertemente vinculados, ya que la capitación anual se descontaba de lo que se debía a cada indio por sus jornales como mitayo. Una vez deducidas esas cargas, los indígenas podían contar con algún sobrante a su favor, que a menudo les fue abonado con retraso y casi siempre en especie. Los mitayos de Santa Cruz recibían, en teoría, $1 \frac{1}{2}$ real por jornada de trabajo. A los efectos de comparar su remuneración con la de los trabajadores libres, puede recurrirse a los informes de la reparación de las fortificaciones de Buenos Aires, donde en 1713 el jornal de un albañil era de 1 peso y el de un peón de 3 reales. Pero ese 1 1/2 real diario no era más que una unidad de cuenta, ya que en casi todos los casos fue abonado en textiles o en cabezas de ganado, y sólo en contadas ocasiones en plata. En 1709 y 1710, de acuerdo con la liquidación de sus jornales que hizo la Real Hacienda, el componente-metálico se mostró escasísimo: $92,2 \%$ se compuso de textiles, 5,8\% de plata y $2 \%$ de cuchillos, frenos y otros utensilios de trabajo. Resulta claro que para esas comunidades indígenas, la subsistencia debió asegurarse por otros medios. En Santiago del Baradero, sus habitantes recibieron licencia de las autoridades españolas para la captura de ganado cimarrón, que era aún abundante en la llanura pampeana. También los quilmes y los acalianes, que trajeron de los valles calchaquíes hábitos alimentarios básicamente agrícolas, debieron adaptarse al consumo de carne. Como veremos luego, la adopción de una dieta fundada en las proteínas de origen vacuno permitió redoblar la explotación de la mano de obra indígena, ya que los mitayos no debían distraerse en la producción de alimentos y pudieron concentrarse en servir al gobernador.

Desde fines del siglo XVII, los jornales de los mitayos eran pagados en textiles, tendencia que se acentuó a comienzos de la siguiente centuria. Cuando el gobernador Valdés Inclán se sirvió de varios indios quilmes en una expe-

27 Cargo puesto contra el corregidor de los Quilmes en el juicio de residencia a Manuel de Prado y Maldonado, 7 de agosto de 1701, AGN Sala IX, Legajo 41-9-5, Exp. 1.

28 Demanda que puso el protector de los naturales a Alonso de Valdés, AGN Sala IX Legajo 1-1-3 Exp. 15. 
dición a las Salinas, éstos recibieron a cambio 36 varas de pañete ${ }^{29}$. También utilizó mitayos quilmes para la reparación del fuerte, a los que pagó «en géneros de bayetas de la tierra $»^{30}$. ¿Se debía esa aceptación a que la indumentaria de estos indígenas se hallaba parcial o totalmente españolizada? Palermo y Boixadós recogen el caso del cacique quilme Agustín Filca, quien se declaró en su testamento poseedor de vestidos de paño y holandilla, monteras, camisas y medias de seda, y sugieren que en el uso de estas prendas se comprobaba su adaptación a las normas del prestigio español ${ }^{31}$. No faltan otros ejemplos: el cacique acalián Martín de Anchoca, que pretendía que el derecho de señoraje que le debían los mitayos le fuera abonado «en plata o en bretaña», pidió finalmente que le fueran libradas varias varas de lienzo de algodón, bretaña y pañete en los almacenes del gobernador ${ }^{32}$. Es indudable que los indígenas fueron asimilando las pautas culturales de sus dominadores, que empezaron siendo aceptadas por los caciques y luego se extendieron a los demás.

Pero a nuestro entender, la difusión de textiles europeos entre los mitayos se debió en menos a la inclinación de los indígenas a adoptar los hábitos de los españoles que a las prácticas de reparto llevadas a cabo por las autoridades de Buenos Aires. Si sus jornales fueron abonados con frecuencia en pañete o bretaña se debió a que éstos abundaban en los depósitos estatales, donde también se proveía a los soldados del Presidio de Buenos Aires. Gracias a su activa participación en el contrabando con los franceses, tanto el gobernador Valdés Inclán como su sucesor Velasco y Tejada disponían de una abundante reserva de textiles, que distribuyeron entre soldados y mitayos a cambio de retener el metálico que correspondía a su paga. Los almacenes del gobernador Velasco y Tejada, administrados por el mercader Antonio Meléndez de Figueroa, cumplieron, efectivamente, un activo papel en la paga a los mitayos. En 1711, por ejemplo, Velasco le ordenó que repartiera bayeta y bretaña a los indios quilmes que participaron de una vaquería ${ }^{33}$. Esto explica que la tienda de Meléndez fuera a menudo mencionada por los libros manuales de la Real Hacienda en las cuentas de la administración de la mita. La preponderancia de los textiles en la composición de los jornales fue, en conclusión, el resultado de las condiciones imperantes en

29 Capítulo que puso Joseph de Narriondo en la residencia de Alonso de Valdés, 3 de mayo de 1708, AGN Sala IX, Legajo 39-9-5, Exp. 8.

30 Declaración del protector de naturales Francisco de Tagle Bracho en el juicio de residencia de Alonso de Valdés Inclán, 10 de diciembre de 1708, AGN Sala IX, Legajo 1-1-3, Exp. 2.

31 Palermo y Boixadós, 6 (Tandil, 1991): 28.

32 Cuenta de los pagamentos hechos a los indios quilmes, 12 de septiembre de 1712, AGN Sala IX, Legajo 41-3-8, Exp. 6.

33 Ibidem. 
Buenos Aires a partir de 1700, cuando la existencia de un sobrestock de mercancías europeas permitió su reparto entre soldados e indígenas, circunstancia que hubiera sido inimaginable una o dos décadas atrás.

\section{SOBREEXPLOTACIÓN Y MODIFICACIÓN DE LA DIETA ALIMENTARIA}

La sobreexplotación a que fue sometida la población de estos reales pueblos a comienzos del siglo XVIII puede encontrar una explicación en la imposición de nuevos hábitos alimentarios, fundados en las proteínas de origen animal. Al encarar la temática de la alimentación es siempre necesario desentrañar los factores, no sólo culturales y económicos, sino también histórico-políticos, que explican sus limitaciones o preferencias en la utilización de los recursos disponibles. En el caso de los indígenas de Buenos Aires deben separarse dos grupos con experiencias diferenciadas. Por un lado, las antiguas etnias de cazadores-recolectores pampeanos, entre las cuales apenas hubo un atisbo de neolitización antes de la conquista; por otro, los quilmes y acalianes deportados a esta ciudad en la década de 1660, que traían prácticas agrícolas de los valles de los que eran oriundos.

Desde sus más tempranos contactos con los conquistadores, los indígenas pampeanos agregaron la carne de yegua a una dieta que estaba ya basada en proteínas animales, provenientes de la cacería de venados y otras especies vernáculas. En 1620, al visitar las reducciones del Bagual, Tubichaminí y Baradero, el gobernador Góngora constató que sus habitantes subsistían fundamentalmente de la captura de cérvidos, guanacos y potrancas cimarronas. Sólo los chanás del Baradero consumían además algo de maíz, que habían aprendido a cultivar de los guaraníes antes de la llegada de los españoles, y un poco de pescado $^{34}$. Sin hacer mayor distinción entre unos y otros, el gobernador Céspedes afirmaría en 1629 que los aborígenes de las cercanías de Buenos Aires se sustentaban «de raíces, carne y sangre de caballo a medio asar, de venados, avestruces y otras cazas y de pesquerías $»^{35}$.

Durante el transcurso del siglo XVII, los hábitos alimenticios de las etnias pampeanas no experimentaron modificaciones sustanciales. La principal variante que se produjo fue la paulatina incorporación del consumo de carne vacuna, conforme crecían los rebaños de ganado cimarrón. Los testimonios de los españoles insisten en atribuirles rasgos de primitivismo, tanto por su moda-

34 Coinciden en resaltar la incidencia cultural de los guaraníes sobre los chaná-mbeguá:

Conlazo, 1982: 67-73. Pi Ugarte, 1995: 62.

35 Marfany, 1941: 43. 
lidad de preparación de los alimentos como por las formas de consumo. Mostraban rechazo por su manera de preparar la carne, que no asaban, sino ahumaban o desecaban. El cura de españoles de la Catedral de Buenos Aires, Gregorio Suárez Cordero, afirmaba en 1680 que los naturales de las pampas «se sustentan con carnes de animales que cazan que comen cruda y seca al sol» ${ }^{36}$. En 1691 otro religioso, el jesuita Antonio Sepp, refería que «no comen otra cosa que carne vacuna sin pan ni sal, casi completamente cruda». De la res, decía éste, desechaban la cabeza, las vísceras y las patas, y cortaban largas tiras de carne que comían apenas pasadas por el fuego. Capturaban a los animales de la misma manera que los peones españoles en las vaquerías: los sujetaban con lazos y los hacían caer cortándole los tendones, validos de un instrumento cortante que describe como "un largo cuchillo», mejor conocido en estas provincias como desjarretadora ${ }^{37}$.

A comienzos del siglo XVIII, los aborígenes pampeanos seguían sosteniendo una dieta con predominio de proteínas vacuna y equina, incluso aquellos que estaban reducidos a encomienda desde hacía una o más generaciones. Al serle confiscada en 1711 la estancia en que se levantó la reducción de San Francisco Xavier, el capitán Gregorio de Matos se quejó de que los aborígenes depredaban a diario sus rebaños: el «gentío pampa», afirmaba, «no sólo come la vaca y la ternera, sino el potro, la mula y el caballo, y mata la yegua para sacar el cuero para su vestuario y toldos $\rangle^{38}$. Es cierto que el general Joseph Ruiz de Arellano, que condujo a los indios encomendados hasta ese paraje, les hizo entrega de bizcocho y harina, pero estos no parecen haber tenido más que un carácter de gratificación, pues no se vuelve a hacer mención de ellos. Al disponer la fundación de San Francisco Xavier, el gobernador Velasco y Tejada prometió ocuparse de la alimentación de sus habitantes, proveyéndolos de ganado vacuno «para que no les falte en el interín que dispongo se les dé en la misma forma que se hace con los pueblos de indios que se hallan en esta jurisdicción agregados a la Real Corona» ${ }^{39}$.

36 Torre Revello, 1941, 288.

37 Al describir Sepp el festín indígena en torno a la hoguera no le falta un toque de repulsión europea: «encienden fuego con plantas de cardos, y mientras aquellos destripan los animales, estos ya van cortando con sus cuchillos tiras de carne, que ensartan en una varilla de madera y mantienen un rato sobre el humo y el fuego, las dejan calentar apenas y ya las llevan al hocico glotón, devorándolas mientras por todos lados chorrea la sangre»; Sepp, 1971, I: 120

38 Presentación de Gregorio de Matos contra Manuel de Velasco y Tejada, 3 de enero de 1713, AGN Sala IX, Legajo 39-9-7, Exp. 5.

39 Acta de fundación del real pueblo de San Francisco Xavier, 9 de abril de 1711, AGN Sala IX, Legajo 39-9-7, Exp. 5. 
Los quilmes y acalianes, como hemos referido, traían consigo prácticas agrícolas de los valles calchaquíes, pero debieron adaptarse aquí al consumo de la carne, inusual en la región de la que eran oriundos. Hay evidencias de ese proceso de adaptación en los testimonios de la demanda que puso el protector de los naturales Francisco de Tagle Bracho en el juicio de residencia del gobernador Valdés Inclán contra la explotación a que se vieron sometidos los habitantes de Santa Cruz de los Quilmes ${ }^{40}$. Afirmaba Tagle Bracho que a estos indígenas, fundamentalmente agricultores, se los había obligado a trabajar como mitayos la mayor parte del año, a causa de lo cual debieron abandonar sus labranzas. Alegaba el protector que «el sustento más natural de dichos indios es el maíz y legumbres por ser originarios de donde no hay ganado vacuno, sino el que se lleva de esta ciudad y la de Santa Fe y pasa por la provincia de Tucumán hasta el Perú». Pero al ser interrogados, los indios respondieron que «su sustento natural ha sido siempre el maíz, el trigo, porotos y todo género de legumbres, y también la carne». Esto dio pie a que el defensor de Valdés Inclán, Francisco Martínez de Salas, arguyera que estos «dicen que igualmente lo es la carne, el maíz y el trigo, y así lo debe ser habiendo tantos años que dejaron su natural y siendo hoy los más de dicha reducción naturales criados con el mantenimiento más ordinario en ella que es la carne» ${ }^{41}$.

La primera generación de quilmes y acalianes nacidos en esta reducción se había adaptado a una dieta compuesta por carne vacuna y por leguminosas - ambas ricas en proteínas de alto valor biológico - y también por cereales. Los caciques y el protector de indios afirmaban que las siembras en Santa Cruz de los Quilmes había arrojado, años atrás, un excedente, que los indígenas habían conducido a Buenos Aires para comercializarlo. Observaba el cacique acalián Martín Salchica que hasta los tiempos del gobernador Agustín de Robles estos naturales tuvieron sobrantes de trigo y maíz, y «lo que cogían, trayéndolo a esta ciudad, lo vendían y con su importe se vestían». Pero Martínez de Salas alegaba que también Valdés Inclán les había dado tiempo para sembrar y cosechar, y que no había obstaculizado su costumbre de pasar con el grano a la ciudad, «pues todo el año venden y han vendido públicamente por las calles de esta ciudad trigo, maíz y todo género de legumbres».

40 Declaración de Francisco de Tagle Bracho en el Capítulo puesto por el protector de los naturales a Alonso de Valdés, 10 de noviembre de 1708, AGN Sala IX, Legajo 1-1-3, Exp. 2.

41 Declaración de Francisco Martínez de Salas en el Capitulo puesto por el protector de los naturales a Alonso de Valdés, 10 de noviembre de 1708, AGN Sala IX, Legajo 1-1-3, Exp. 2. 
Varias son las conclusiones que podemos extraer de estos testimonios. Es innegable que los quilmes y acalianes aceptaron una dieta rica en proteínas animales, pero aunque ésta llegó a predominar frente al maíz y al trigo nunca pudo desplazarlos por completo. El alto contenido energético de estos cereales los hizo insustituibles, especialmente después de que se trastocó el sistema de la mita y se les impuso un régimen de trabajo mucho más riguroso. Los indígenas siguieron cultivando trigo y con él hacían pan: así lo afirmaba en el juicio a Valdés el cacique acalián Martín Salchica. Idéntico destino debía tener la ración de semita o salvado menudo que el Hospital Real repartía entre los mitayos quilmes que servían en él ${ }^{42}$.

Resulta obvio que las autoridades españolas tenían un especial interés en que los mitayos y sus familias se adaptaran a una dieta predominantemente cárnea. Ello permitía a los gobernadores absorber una mayor cantidad de días-hombre, ya que la recogida de ganado cimarrón insumía menor cantidad de tiempo que el tradicional cultivo del maíz, y al no ser estacional como éste, facilitaba la disponibilidad laboral del grupo a lo largo de todo el año. En 1713, por ejemplo, una comisión conformada por el ingeniero militar y dos cabildantes, encargada de evaluar los gastos de reparación del fuerte de Buenos Aires, calculaba un consumo diario de una vaca por cada veinticinco mitayos. Esta estimación podría parecer exagerada, si no se tuviera en cuenta que entonces sólo se consumían algunos cortes de la res, y el resto se desechaba. La manutención de los mitayos de Santa Cruz de los Quilmes acarreaba de esa manera el degüello de menos de mil reses por año.

La sobreexplotación que sufrieron los quilmes y acalianes redundó en la recreación de nuevas estrategias comunitarias para la producción agrícola, ya que al abandonar los sembrados para servir en forma casi permanente como mitayos, los hombres debieron delegar el cuidado de los cultivos en las mujeres, los viejos y los niños. El hecho de que aun en esas condiciones la producción de maíz y trigo siguiera brindándoles un pequeño excedente comerciable es otro indicador de que su dieta ya no predominaba en hidratos de carbono, sino en proteínas animales. Hasta el gobierno de Agustín de Robles, los habitantes de Santa Cruz de los Quilmes no sólo cultivaban cereales para procurarse un suplemento energético, sino para venderlo en la ciudad y conseguir algo de metálico para gastos de indumentaria. Según declaró el cacique Martín de Anchoca en 1707, esa había sido la manera en que habían adquirido tradicionalmente su vestimenta. No obstante, desde principios del siglo XVIII, cuando el contrabando generalizado con los franceses saturó la plaza de texti-

42 Birocco, 2000: 30-37. Para los distintos tipos de pan consumidos durante la colonia en Buenos Aires: Garavaglia, III: 4 (Buenos Aires, 1991): 16. 
les europeos, ya no se vieron obligados a vender trigo y maíz para proveerse de tejidos, sino que los mismos le fueron entregados como pago de sus jornales como mitayos. Los gobernadores de Buenos Aires consiguieron mediante la provisión de reses y el reparto de textiles que estos indígenas no distrajeran esfuerzos en la consecución de alimento y vestido, y de esa forma pudieron incrementar al máximo la cantidad de días-hombre exigida en el servicio de mita.

\section{CONCLUSIÓN}

En Buenos Aires, la población indígena tributaria tuvo un origen heterogéneo. A las etnias guaranitizadas de las zonas cercanas a costa del Paraná se agregaron algunos grupos de querandíes del interior de la llanura pampeana y, décadas más tarde, unos pocos cientos de quilmes y acalianes, traídos de los valles calchaquíes de donde eran oriundos. Con excepción de estos últimos y de los que fueron asentados en la reducción de Baradero, los demás grupos habían desaparecido hacia 1720, ya que el reducido número de individuos que los conformaban les impidió consolidarse y los obligó a mezclarse con el resto de la población mestiza de la región.

La experiencia de la encomienda en Buenos Aires tuvo corta vida, interrumpida por la creciente injerencia de las autoridades locales, que se apropiaron de la mano de obra indígena organizándola en reales pueblos de indios y explotándola por medio del sistema de la mita. Al ser colocados bajo el control directo de los gobernadores, la presión sobre los naturales se hizo cada vez mayor, particularmente en el caso de los quilmes y acalianes, a quienes se utilizó en las expediciones de caza de ganado cimarrón, en los acarreos de materiales para el fuerte y otras tareas no especializadas. La reglamentación de la mita, que en un principio garantizaba a estos indígenas la disposición del tiempo necesario para emprender sus labores agrícolas — que, por otra parte, eran protegidas y fomentadas por la Corona - fue modificada por los sucesivos gobernadores. La estrategia de estos consistió en habituar a los mitayos y sus familias al consumo de proteínas vacunas, ampliamente disponibles gracias a la abundancia de ganado cimarrón, y apropiarse de su fuerza de trabajo durante la mayor parte del año, lo que no hubiera podido lograrse si les hubiesen permitido seguir subsistiendo de la agricultura. Los indígenas se adaptaron así a una dieta fundamentalmente cárnea, aunque complementándola con la ingesta de farináceas, y al serles exigido un número mayor de días de trabajo, se vieron forzados a depositar el cuidado de los cultivos en las mujeres y niños de sus comunidades. Pero la modificación de sus hábitos alimenticios, gracias a 
la cual disminuyó su consumo de trigo y maíz, les permitió derivar hacia el mercado de Buenos Aires sus excedentes de grano y adquirir con su venta vestidos y otros objetos, haciendo propias las pautas de consumo que copiaron de los españoles.

\section{BIBLIOGRAFÍA}

Actis, Francisco, Actas y documentos del Cabildo Eclesiástico de Buenos Aires, Buenos Aires, Edición del Obispado, 1943.

Birocco, Carlos María, «Historia de un latifundio bonaerense: las estancias de Riblos en Areco, 1713-1813», Anuario de Estudios Americanos, Escuela de Estudios Hispanoamericanos, LIII/1 (Sevilla, 1996): 73-91.

Birocco, Carlos María, «La primer casa de recogimiento de huérfanas de Buenos Aires: el beaterio de Pedro de Vera y Aragón (1692-1702)», José Luis Moreno (ed.), La política social antes de la política social. Caridad, beneficencia y política social en Buenos Aires, siglos XVII a XX, Buenos Aires, Trama, 2000: 21-46.

Canals Frau, Salvador, Las poblaciones indigenas de Argentina, Buenos Aires, Hyspamérica, 1986.

Conlazo, Daniel, Los indios de Buenos Aires, siglos XVI y XVII Buenos Aires, Búsqueda-Yuchán, 1982.

Contreras, José, Antropología de la alimentación Eudema, Madrid, 1993.

Esteva Fabregat, Claudio, El mestizaje en Iberoamérica, Madrid, Alhambra, 1988.

Garavaglia, Juan Carlos, Mercado interno y economía colonial, México DF, Enlace-Grijalbo, 1983.

Garavaglia, Juan Carlos, «El pan de cada día: el mercado del trigo en Buenos Aires, 1700-1820», Boletín del Instituto de Historia Argentina y Americana Dr. Emilio Ravignani, III/4 (Buenos Aires, 1991): 11-27.

González Lebrero, Rodolfo, «Producción y comercialización del trigo en Buenos Aires a principios del siglo XVII», Boletín del Instituto de Historia Argentina y Americana Dr. Emilio Ravignani, III/11 (Buenos Aires, 1995): 7-37.

González Lebrero, Rodolfo, La pequeña aldea, Sociedad y economía en Buenos Aires (1580-1640), Buenos Aires, Biblos, 2004.

Gracia, Mabel, «Antropología de la alimentación», Prat, Joan y Martínez, Ángel Ensayos de antropología cultural. Homenaje a Claudio Esteva-Fabregat, Barcelona, Ariel, 1996: 151-182.

Hernández, Isabel, Los indios de Argentina, Madrid, Mapfre, 1992. 
Mandrini, Raúl, «Las transformaciones de la economía indígena bonaerense (ca.16001820)», Raúl Mandrini y Andrea Reguera (comps.), Huellas en la tierra. Indios, agricultores y hacendados en la pampa bonaerense, Tandil, Universidad Nacional del Centro de la Provincia de Buenos Aires: 45-74.

Marfany, Roberto, El indio en la colonización de Buenos Aires, Buenos Aires, Comisión Nacional de Cultura, 1941.

Mörner, Magnus, La Corona Española y los foráneos en los pueblos de indios de América Madrid, Ediciones Cultura Hispánica, 1999.

Palermo, Miguel Ángel, «La innovación agropecuaria entre los indígenas pampeano patagónicos: génesis y procesos», Anuario de I.E.H.S., Universidad Nacional del Centro de la Provincia de Buenos Aires, 3 (Tandil, 1986): 43-90.

Palermo, Miguel Ángel y Boixadós, Roxana, «Transformaciones en una comunidad desnaturalizada: los Quilmes, del valle calchaquí a Buenos Aires», Anuario de I.E.H.S., Universidad Nacional del Centro de la Provincia de Buenos Aires, 6 (Tandil, 1991): 13-42.

Peña, Enrique, «Don Francisco de Céspedes. Noticias sobre su gobierno en el Río de la Plata (1624-1632)», Anales de la Academia de Filosofía y Letras, V (Buenos Aires, 1916): 140-177.

Pi Ugarte, Renzo, Los indios de Uruguay, Cayambe (Ecuador), Mapfre-Abya Yala, 1995.

Saguier, Eduardo, «El mercado de mano de obra indígena, liberta y mestiza y su impacto en la estabilidad del Estado colonial. El caso de las encomiendas del interior del espacio colonial rioplatense», Cuadernos de Historia, 13 (Santiago de Chile, 1993): 69-140.

Sepp, Antonio S.J., Relación de viaje a las misiones jesuíticas, Eudeba, Buenos Aires, 1971.

Sors de Tricerri, Guillermina, Quilmes colonial, La Plata, Archivo Histórico de la Provincia de Buenos Aires «Ricardo Levene», 1937.

Torre Revello, José, Documentos históricos y geográficos relativos a la conquista y colonización rioplatense, Buenos Aires, Centenario-Jacobo Peuser, 1941.

Torre Revello, José, «Las encomiendas de indios tubichaminís y vilachichiz», Homenaje a Monseñor Pablo, Córdoba (Argentina), Universidad Nacional de Córdoba, 1963: 220-245.

Fecha de recepción: 11-7-2007

Fecha de aceptación: 19-2-2008 


\section{THE INDIGENOUS POPULATION OF BUENOS AIRES AT THE BEGINNING OF THE EIGHTEENTH CENTURY: THE REALES PUEBLOS DE INDIOS AND THE DECLINE OF THE ENCOMIENDA}

During the seventeenth century, infectious diseases, desertion, and intermarriage were taking their toll on the encomiendas of Buenos Aires. At the beginning of the following century, the few indigenous groups that were still subject to the encomienda system were settled in towns by the royal administration and organized according to the mita system. They were thus administered textiles and a diet rich in bovine proteins in order that they might concentrate their efforts more effectively on their mita duties, rather than on their own agricultural efforts.

KeY Words: Buenos Aires, Royal Indian Towns, Mita system, nutrition. 